\title{
The Other: Exploring the Life of An Intersex Individual in A Stigmatizing and Discriminating Society
}

\author{
Carissa Adelia Novinna \\ English Department, Faculty of Languages and Literature, Petra Christian University, Siwalankerto 121-131, \\ Surabaya 60236, Indonesia. \\ E-mail: m11416054@john.petra.ac.id
}

\begin{abstract}
This creative thesis aims at showing the effects of stigma and discrimination on intersex individuals and how they can lessen the effects of stigma and discrimination through the medium of a screenplay titled The Other. I apply the theory of stigma as the main foundation of the creative work and the theory of self-acceptance as the resolution. Utilizing the genre drama and the conventions of modern youth films, I employ the main character's suffering and contentment accordingly to highlight the detrimental consequences of stigma and the psychological gain of self-acceptance. The Other follows Alexander Wijaya, then 16 years old, a boy who embarks on a self-discovery journey after discovering his intersexuality. As he faces bullying and other grievances, Alex begins to have self-doubt and feel ashamed and isolated. Later, Alex realizes his worth and retrieves back his confidence after he decides to accept his body the way it is.
\end{abstract}

Keywords: Intersex, Stigma, Discrimination, Self-acceptance.

\section{INTRODUCTION}

A screenplay is the core of a movie, a base for what appears on the screen, both seen and heard which includes a film's structure, its dialogue, and a description of the scene's most significant action. A film is a story with pictures that engages people in an emotional situation that they can relate to. Throughout the years, motion pictures have become the primary mode of spreading information and educating audiences (Drucker, 2012). Stories presented in films have the potentials to bring voices and knowledge through visual technological language to life that can raise social awareness and create a connection between individuals. "It is almost impossible to envision a good film with a bad screenplay" (Richards, 2010). A film and a screenplay are hence inseparable, so to produce a film that can encourage people to be more vocal about certain issues that need to be addressed, it is crucial to begin with writing a good screenplay. By displaying my story in the form of a screenplay, I hope that the audience can get a better understanding of how raw and real the struggles that my characters face in the story despite them being fictional characters.

I decide on drama for my screenplay, a genre that usually deals with real-life issues, a conflict whether internal or external, and aims to tell an authentic human struggle (Buffam, 2011). A dramatic movie generally discusses explosive issues of the time, such as societal ills, injustice, sexual inequality, and more (Dirks, n.d.). By using drama, I would like to enhance the severity of the topic of my story and shows its degree of realism which comes in parallel with the aim of a drama movie itself.

In this creative thesis, I will dig deeper into finding how intersexes try to live in today's society that stigmatizes and discriminates against them. The goals of my work are to understand the effects of being stigmatized and discriminated, and how intersex individuals can lessen these effects. 
Novinna: The Other: Exploring the Life of An Intersex Individual in A

Stigmatizing and Discriminating Society

In English, sex and gender refer to different concepts. Unlike sex, someone's gender is not assigned by genetics but rather developed in response to their environment, including family interactions, the media, peers, and education (Newman, 2018). In short, sex is biologically constructed, and gender is socially developed. These two terms are frequently mixed up, and a lot of people are still unfamiliar with them. Society often fails to realize that there are millions of people around the world that were born with sexual characteristics that do not belong in the typical accepted binary notions of male or female bodies. Though not all, many of these people identify as intersex. "Intersex is a general term used for a variety of conditions in which a person is born with reproductive or sexual anatomy that doesn't seem to fit the typical definitions of female or male" (What is intersex?, n.d.). These characteristics could be physically identified at birth, puberty, or not apparent at all. There are many different gender identities for intersexes, and what bonds them is the fact that they were born with anomalous and stigmatized sex characteristics that do not meet stereotypical expectations for men or women.

Intersex people often experience prejudice and discrimination because their bodies do not conform to other people's expectations about sex and gender. As a massively underrepresented and still widely misunderstood group (Its Intersex Awareness Day - here are 5 myths we need to shatter, 2018), intersex people are forced to conform to the unjustly reinforced fixes such as gender stereotypes due to the common society's misconception of their identities, which tend to function as a measurement of one's competency and worth. Other than that, it is also used to determine what is normal in society. This causes society to diffusely isolate intersex individuals who are not included in both socially accepted binaries.

The perception of gender and sex in a binary way is also very prevalent in Indonesia. Although gender and sexual diversity are inherent in Indonesian societies, and culturally, Indonesians have recognized sexual and gender diversity as part of their daily lives, the term intersex in Indonesia is still considered new. Indonesian local media tends to use the term kelamin ganda or 'doublesex' when discussing intersex (DKP, 2019), which gives a stigma to intersex and would often make them choose to keep their existence in silence for safety and to avoid the public's judgment. Most Indonesians misunderstand the concept of intersexuality due to a lack of knowledge, valid information, and research in the related field. A lot of Indonesian parents also think that discussions about sexes and sexualities as taboo, forcing intersex children to be introverted. Another common factor that causes intersex children to avoid 'coming out' is the practice of bullying and name-calling that leads to them feeling ashamed of their condition. Pressuring actions of such and the stigma that is ingrained in the society prompt intersexes to refrain themselves from getting their conditions known to the public. Many intersex children go through surgery in efforts to 'normalize' their bodies although these interventions are often invasive as they are too young to participate in giving consent about their own bodies. The surgeries are also irreversible, not performed for emergency reasons, and are likely to cause major problems like infertility and lifelong psychological trauma.

In brief, my artwork will develop around Alex, then 16 years old, a boy who has spent his life going in and out of hospitals and taking medications. When he returns to school, Alex finds out about his physique 'abnormalities' through force and begins suffering from bullying. At home, he does not have a say in almost every matter and tries to conceal his passion for the art of makeup that his father loathes.

For the theoretical framework, I use two theories. First, the theory of stigma by Erving Goffman. Goffman defines stigma as an attribute that discredits an individual, reducing him or her 
"from a whole and usual person to a tainted discounted one" (Stigma: Notes on the Management of Spoiled Identity, 1963, p. 3). A stigmatizing attribute designates the bearer as "spoiled" and therefore as less valuable than "normal" people. In Goffman's theory of social stigma, a stigma causes an individual to be mentally classified by others in an undesirable, rejected stereotype rather than in an accepted, normal one. Goffman describes stigma as a phenomenon whereby an individual with an attribute that is deeply discredited by their society is rejected as a result of the attribute. He views stigma as a process by which the reaction of others spoils normal identity, and what constituted this attribute changes over time. Stigma is therefore something that is socially assigned.

Erving Goffman (1963) describes stigma as consisting of (a) tribal identities, such as race and ethnicity, (b) abominations of body, such as physical abnormalities, and (c) blemishes of individual characters, such as mental illness and addiction. Since Goffman's era, social psychology has contributed to the awareness of stigma on ethnicity, gender, sexual orientation, and health conditions through the application of the social-cognitive model. According to the social-cognitive model, there are three components of stigma formation. They are stereotypes, prejudice, and discrimination. Stereotypes are public attitudes in categorizing people, for instance, most people think intersex children's bodies need to be 'normalized'. Prejudice is the emotional reaction resulting from the agreement with public attitudes, for example, "Yes, intersex children need to correct their bodies, and I feel weirded out by their ambiguous sex." Discrimination is the behavioral product of stereotypes and prejudices, for instance, intersex children get subjected to irreversible, unconsented, and unnecessary surgeries.

For stigma to take place, firstly, the public has to distinguish and label the difference between themselves and the stigmatized group (Link \& Phelan, 2001, p. 367). In some stigmatized groups, such as people of color, group membership is readily evident. When an individual is identified to be a member, or a potential member, of a stigmatized group, the stereotypes that are attached to that group are initiated, and that individual is considered or labeled as a group member. If the cultural environment perceives the label as negative, and there is a disparity between the stigmatizer and the stigmatized, the stigma will thus occur (Link \& Phelan, 2001, p. 370). In stigmatization, "marks" become linked with "discrediting dispositions"-negative evaluations and stereotypes (Jones, et al., 1984). These stereotypes and evaluations are generally widely shared and well known among members of a culture (Crocker, Major, \& Steele, 1998), and they become a basis for excluding or avoiding members of the stigmatized group which results in the form of discrimination.

It is likely for a stigma to negatively affect a person's self-concept. A stigmatized self could become salient depending on their actions and behaviors such as "being aware of and sharing, negative cultural evaluations of the stigma and applying these to themselves, or their attending to the reactions of others, interpreting these in terms of the stigma, and incorporating these negative evaluations into their self-concept (Finlay, 1999, p. 30). The impacts of having a stigmatized identity that leads to lowered self-esteem are seen as somewhat straightforward responses to the trait. The affiliation between members of the stigmatized groups and lower self-esteem is often suggested in social psychology, such as in Social Stigma (Crocker, Major, \& Steele, Social Stigma, 1998). The power stigma holds is regarded to be so great that it is tough to prevent the consequences towards the self-concept (Jones, et al., 1984). As summed by Goffman (1963), for the reason that a stigmatized person in our society obtains identity standards that they apply to themselves despite failing to conform to them, feeling some ambivalence and doubts about their selves is unavoidable. 
Novinna: The Other: Exploring the Life of An Intersex Individual in A

Stigmatizing and Discriminating Society

The theory of stigma will be presented in my work as the foundation of my screenplay. Since the main character of my story, Alex, is an intersex, the stigma that will take place is the one of (publicly regarded as) physical abnormality. Then, in my screenplay, all three components of stigma formation, namely stereotypes, prejudices, and discrimination, are going to be shown in sequence as well. Also, the relationship between stigma, prejudice, and discrimination as explained above will be the tool that keeps the narrative moving, and as the base of events Alex goes through in the story.

Second, the theory of self-acceptance. Self-acceptance in general is theorized as an affirmation or acceptance of one's self despite weaknesses or deficiencies. A person can attain selfacceptance by putting an end to criticizing and resolving one's defects, and then accepting these flaws to be existing within one's self, meaning to tolerate imperfections in some parts (Shepard, 1979). In the humanistic psychology literature, self-acceptance pervasively occurs at an implicit level, but it is the foundation of much of humanistic theory and has been crucial in the development of humanistic psychology. The two founders of humanistic psychology, Abraham Maslow and Carl Rogers place a great emphasis of self-acceptance in their works namely the self-actualization of individuals to their very self. Maslow states that self-acceptance occurs through the actualization of the self, which is the result of the discovery and development of the self (Goble, 1970). Furthermore, he thinks that self-acceptance is required as he considers it as a journey of selfdiscovery before reaching the state of self-actualization. Maslow places self-actualization on the top of his Hierarchical Needs that are organized in different levels where the lower needs, which required interaction with other people, must first be fulfilled to move to the next one. Thus, the highest level in Maslow's Hierarchical Needs is about achieving one's full potential and through this achieving self-acceptance (Hoffman, Lopez, \& Moats, 2013).

Similar to Maslow, the basic principle for Roger's theories is to aid individuals to achieve their maximum potential as humans (Client-centered Therapy, 1951). Rogers too believes that a person can find self-acceptance within oneself through interrelationships with other people, particularly exemplified in the therapeutic relationship, and this would bring about positive results (The Process of Therapy, 1940). Rogers thinks that this particular scenario is rarely attained in the real world where society may be unable to offer this type of support (1951). As a result, Maslow sees that there is a need for one to satisfy lower-level needs that include relationships with others to acquire self-acceptance and self-actualization. Self-actualizing is about striving to make use of one's potentials, "which sometimes is best expressed in the acceptance of one's helplessness or limitations" (2013, p. 6). It is not a one-time occurrence, but rather an ongoing process. According to Rogers, openness to experiences is a vital starting point that should be paired with an acceptance of them. In short, the acceptance of experiences in life and oneself is a crucial component of selfactualization.

Other than self-actualization, self-acceptance is also strongly correlated to self-esteem. However, more recent studies and theories have advised the importance of distinguishing the two (Bernard, 2013). Stanley Coopersmith (The Antecedents of Self-esteem, 1967) refers to self-esteem as how much an individual likes or values the self, based on correspondence with one's own standards or on comparisons with others. Self-esteem is differentiated between stable or trait and contingent or unstable (state) self-esteem (Deci \& Ryan, 2000). The pursuit of self-esteem is mostly focused on the state instead of the trait self-esteem (Crocker \& Park, 2004). As a result, most people suffer from low self-esteem for evaluating their worth based on the degree of success in getting others' validation and approval. Inadequate or excessive self-esteem is linked to a variety of problems. In comparison, self-acceptance has been claimed as a healthier psychological attribute 
than self-esteem. In The Myth of Self-Esteem, Albert Ellis, the forefront of the psychotherapeutic community, writes about self-acceptance:

People's estimation of their own value, or worth, is exceptionally important. If they seriously denigrate themselves or have a poor self-image, they will impair their normal functioning and make themselves miserable in many significant ways. When people do not value themselves very highly, innumerable problems arise. The individual's judgment of his own value or worth has such an impact on his thoughts, emotions and actions, how is it possible to help people consistently appraise himself so that, no matter what kind of performance he achieves and no matter how popular or unpopular he is in relations with others, he almost always accepts or respects himself (2005).

In short, a person with self-acceptance is a realistic person who understands themselves and is aware of one's strong points and flaws. When the capability to unconditionally accept oneself is absent, it is likely to lead to "a variety of emotional difficulties, including uncontrolled anger and depression" (Carson \& Langer, 2006, p. 29). Self-acceptance therefore not only signifies an individual's happiness and satisfaction with oneself but is also regarded as essential for good mental health. To summarize, whilst self-esteem holds a substantial role in one's life, self-acceptance is the trait that brings one's self to the places one desire in life. With self-acceptance, a person can tell their weak points while also not letting this understanding interfere with their abilities to fully accept themselves.

My screenplay will deliver the conventions of self-acceptance theory as the method of resolution to Alex's descended concept of self, which is the consequence of stigma and discrimination against him. The attribute of self-acceptance will be visualized in Alex's present life. As for teen Alex, self-acceptance will only get transparent nearing the end of the screenplay. This signals the screenplay's paralleling to the attribute's claim in which self-acceptance is not a single occurrence, but rather a journey.

\section{OUTLINE OF THE CREATIVE WORK}

Several stages need to be fulfilled in constructing a screenplay. It begins with the foundations which include the premise and design principle. Then, it is followed by building the story with a three-point pitch, which will be expanded into a synopsis, and a step outline is formed after. Aside from the outline, there is also a necessity in developing the characters and the basic conflicts of the screenplay. The outline and the screenplay can be found in my thesis: The Other: Exploring the Life of An Intersex Individual in A Stigmatizing and Discriminating Society.

\section{Premise and Design Principle}

\section{Premise}

An intersex individual who is raised as a boy discovers joy through cosmetics and decides to pursue his dream of becoming a professional makeup artist while also accepting his body the way it is.

\section{Design Principle}

The main theme of my creative work is that identifying as an intersex should not be a shameful thing to do and yet to be normalized. Today's society promotes the idea that unless one fits into the convention, one is freaky and worthless. I want to show the audience just how 
Novinna: The Other: Exploring the Life of An Intersex Individual in A

Stigmatizing and Discriminating Society

dangerous stigmatization and discrimination can be on someone and how it strips away one's freedom from being one's true self.

I would like to start the screenplay with a scene of grown-up Alex meeting a writer named Linda. The main story of the screenplay will be written in the form of Alex retelling his past to Linda. Though his teenage self gets a happy ending, nearing the end of the story, Alex will reveal that in the present days, he is still struggling against discrimination. This is to show that in real life, the stigma about intersex people is still going strong. The screenplay will end with Linda offering Alex to work together with her to make his story into a book and publish it. The purpose of this ending is to parallel the screenplay's form with the goal of this creative work, which is aiming to spread awareness regarding intersexes and as an effort to break the stigma.

\section{Pitch}

1. Alex, at the age of 16 , discovers that he is intersex and realizes his growing interest in make-up.

2. While Alex faces his dad's direct disapproval of his future career choice and is urged to fix his physical irregularities, he also faces bullying at school.

3. Alex decides to pursue his dream of becoming a professional make-up artist while also accepting his body the way it is.

\section{Synopsis}

Alexander Wijaya, now 24-year-old, meets Linda for a makeup appointment. During the process, Linda convinces Alex to tell her about his past. Alex, then a 16-year-old high school student, has spent his whole life visiting hospitals and taking pills. Going back to school after missing out for so long leads Alex into finding out about his 'abnormalities'. While trying to figure out his oddness, Alex faces bullying at school. At home, Alex finds joy in expressing himself through the art of makeup. Hartono, Alex's father, is not fond of Alex's passion that he views as too feminine for boys. With the help of Leo, Alex's only friend, Alex battles through bullying and the discovery of his talent. After getting constantly persuaded by Pak Bayu, Alex's homeroom teacher, and Leo, Alex decides to join the annual art competition and wins third place. Hartono sees the joy on Alex's face and chooses to let Alex makes his own decision from then on. Alex gets the chance to know his unique body, pursue his calling in the world of makeup, and finally crosses paths with Linda, who at the end offers Alex to work with her to publish his story.

\section{Characters}

1. Alexander Wijaya, now 24 years old, then 16 years old.

Alexander Wijaya is the only child of Hartono Wijaya and Anggita Mulyadi. He enjoys drawing during his free time and is particularly interested in makeup. Through the art of makeup, he feels that he can express himself more freely. However, his father, Hartono is not fond of this. As an obedient child, Alex tries to listen to his father. Alex is quiet and mostly keeps his problems to himself. He withholds the confusion he has about his own body. Since he misses school most of the time, Alex has no friends. When Alex reaches the age of sixteen, he gains a new friend and slowly gets an answer to the questions he has about himself.

2. Hartono Wijaya, Alex's father, 48 years old.

Hartono Wijaya is a strict and conservative man who thinks that someone's sex, gender, and gender expression should match. He upholds a set of old-fashioned ideals that he forces on Alex. He pressures Alex to be tough, strong, and masculine. He despises Alex's enthusiasm for 
makeup and wants him to switch his passion into something that he thinks is more fitting for a man. He has a furniture shop that he hopes to pass on to Alex when he becomes an adult which is why he tries to get Alex to be interested in the study of interior design.

3. Anggita Mulyadi, Alex's mother, 44 years old.

Though also firm, Anggita is softer towards Alex than her husband. She always helps Alex whenever Hartono is being too hard on him. Anggita tries to fulfill Alex's wishes and demands in any chance she has. She also grows to be more supportive of Alex's aspiration. By the end of the day, Anggita only wants the best for Alex and does not want him to get hurt.

4. Leonard Sultanta, Alex's best friend, 16 years old.

Leo is Alex's first close friend. Unlike Alex, Leo is talkative. He speaks his mind and is straight forward. He is also easily influenced by his surroundings. He gets caught in the dilemma of whether he wants to stick up for Alex when the latter gets bullied or stays as a bystander. After realizing the kind person Alex is, Leo feels apologetic towards Alex and makes up his mind to defend Alex.

5. Jessica Lianto, Alex's nemesis, 16 years old.

Jessica comes from a well-off family. She is spoiled and has quite a temper. She throws tantrums when things are not in her favor. To reach her goal, Jessica does not hesitate to play dirty. She likes being the center of attention and derides people that steal her spotlight.

6. Bayu Adiguna, Alex's homeroom teacher, 35 years old.

Pak Bayu is an attentive teacher. He tries his best to be a fair teacher to his students. He is quick to spot Alex's talent and ability in art and supports Alex to keep his talents.

7. Linda Kurniawan, grown-up Alex's client, 26 years old.

Linda is a curious person by nature. She is a writer and has several accomplishments in the writing field. She loves conversing and getting to know new people. She is open-minded and is keen on helping Alex spread his story.

\section{Conflict}

There are two kinds of conflicts in my screenplay. Both are related to each other. The first one is an external social conflict between Alex and the people around him. Alex wants to feel accepted and not estranged. However, due to his differences, Alex is subjected to bullying. Moreover, his parents, his father, show rejection of Alex's interest and pay no attention to how Alex feels. The second conflict is an internal one or an emotional ordeal. Alex is confused about his physique and cannot understand why his parents always push him to consume pills and get surgeries. He also feels dejected for being stopped from doing what he enjoys. Later, Alex decides to pursue his dream and accepts his body the way it is.

\section{CONCLUSION}

The first initial purpose of this screenplay is to show the effects of stigma and discrimination on intersex individuals. In conformity, The Other presents the protagonist Alex as a person with an intersex condition. To align with the theory of stigma, my screenplay presents all three main components of stigma formation, respectively stereotypes, prejudice, and discrimination. First, in The Other, Alex's surroundings come to realize that he is in possession of anatomy that is socially viewed as uncommon. Second, influenced by the general public attitude, Alex's parents attempt to correct his body with the help of the medical world since he could remember. Then there are also Alex's peers who bluntly express their shock and disgust after finding out about his condition when they ambush him at Jessica's birthday party. Third, Alex goes through a series of unpleasant events 
Novinna: The Other: Exploring the Life of An Intersex Individual in A

Stigmatizing and Discriminating Society

in his life. Alex is discriminated against. He spends a big portion of his life in the hospital getting unconsented surgeries. Additionally, he is instructed to take pills that his parents labeled as vitamins without knowing what they do to his body. Furthermore, he experiences bullying at school after the ambush incident.

Likewise, the three components of stigma formation that are displayed in the screenplay consequently build a series of negative outcomes for Alex. As the story unfolds, Alex struggles with self-doubt, shame, and isolation. When Pak Bayu offers Alex to join a drawing competition, Alex shows hesitation as he doubts his own skill. Alex also shuts himself off and spends most of his time alone. Due to Hartono constantly voicing out opposing remarks to Alex's interest in make-up, Alex becomes uncomfortable with showcasing his hobby openly because he thinks that it is a shameful thing which leads him to do it in secret.

The last purpose of my creative work is to show that intersex individuals can lessen the effects of stigma and discrimination through embracing self-acceptance. The Other brings upon the characteristics of a person in possession of self-acceptance through Alex. Following the narrative, Alex faces the undesirable sides of life such as being stigmatized and discriminated against through a series of incidents like getting unconsented surgeries and bullying at school. As he suffers due to stigma and discrimination, at one point in the story, Alex avoids Leonard despite the latter having apologized for being a bystander to Alex's bullying episodes at school. Alex is afraid of Leonard's rejection should he learn the truth about Alex's body and hobby. He also shuts himself off at home. As explained in the theory section, to find self-acceptance within oneself, a person should build interrelationships with other people. To align with the theory, Alex braves himself against his fear and finally sits down to have a conversation with Leonard. With Leonard's aid, Alex regains his confidence and assures himself of his worth. Alex also gets the courage to stand for himself and talk about his true desire in pursuing an education in a beauty school to his parents. Moreover, gradually, with the help of his family and friends, Alex grows to accept his body and its uniqueness, which demonstrates the application of self-acceptance in The Other. Lastly, to emphasize the screenplay's compliance to the self-acceptance theory, my creative work showcases present-day Alex to be a more positive individual than he is in his teenage days and displays him explicitly saying that going against a society that still holds a deeply ingrained stigma towards intersexes is not easy but yet it becomes more tolerable since his family and friends have his back, which implies to the theory's claim of self-acceptance being a lifelong journey rather than a single event.

\section{REFERENCES}

Buffam, N. (2011, March 14). Drama. Retrieved September 16, 2019, from thescriptlab: https://thescriptlab.com/screenplay/genre/952-drama/

Carson, S. H., \& Langer, E. (2006). Mindfulness and self-acceptance. Journal of Rational-Emotive \& Cognitive-Behavior Therapy, 24, 29-43. https://doi.org/10.1007/s10942-006-0022-5

Coopersmith, S. (1967). The Antecedents of Self-esteem. San Francisco: W. H. Freeman.

Crocker, J., \& Park, L. E. (2004). The costly pursuit of self-esteem. Psychological Bulletin, 130(3), 392-414. https://doi.org/10.1037/0033-2909.130.3.392

Crocker, J., Major, B., \& Steele, C. (1998). Social Stigma. In D. T. Gilbert, S. T. Fiske, \& G. Linzey (Eds.), The handbook of social psychology (4th ed., Vol. 1, pp. 504-553). Boston: McGraw-Hill.

Deci, E. L., \& Ryan, R. M. (2000). The "What" and "Why" of Goal Pursuits: Human Needs and the SelfDetermination of Behavior. Psychological Inquiry, 11(4), 227-268. https://doi.org/10.1207/S15327965PLI1104_01 
Dirks, T. (n.d.). Drama Films. Retrieved September 6, 2019, from Filmsite: https://www.filmsite.org/dramafilms.html

DKP. (2019, August 14). Belajar dari Kawan Interseks. Retrieved from qbukatabu.org: https://qbukatabu.org/2019/08/14/belajar-dari-kawan-interseks/

Drucker, J. R. (2012, November). The Harvard Crimson. Retrieved from Watching, Not Reading.

Ellis, A. (2005). The myth of self-esteem: How rational emotive behavior therapy can change your life forever. New York: Prometheus.

Finlay, W. (1999). Stigma and self-concept: A social-psychological analysis of representations of self in people with learning difficulties. Doctoral dissertation, University of Surrey, Department of Psychology. Retrieved from https://core.ac.uk/download/pdf/101423.pdf

Goble, F. G. (1970). The Third Force: The Psychology of Abraham Maslow. New York: Grossman.

Goffman, E. (1963). Stigma: Notes on the Management of Spoiled Identity. Englewoods Cliff, NJ: PrenticeHall.

Hoffman, L., Lopez, A. J., \& Moats, M. (2013). Humanistic Psychology and Self-Acceptance. In M. E. Bernard (Ed.), The Strength of Self-Acceptance: Theory, Practice, and Research (pp. 3-17). New York: Springer. https://doi.org/10.1007/978-1-4614-6806-6_1

Its Intersex Awareness Day - here are 5 myths we need to shatter. (2018, October 26). Retrieved from Amnesty International: https://www.amnesty.org/en/latest/news/2018/10/its-intersex-awareness-dayhere-are-5-myths-we-need-to-shatter/

Jones, E. E., Farina, A., Hastorf, A. H., Markus, H., Miller, D. T., \& Scott, R. A. (1984). Social stigma: The psychology of marked relationships. New York: W.H. Freeman.

Link, B. G., \& Phelan, J. C. (2001). Conceptualizing Stigma. Annual Review of Sociology, 27, 363-385. doi:10.1146/annurev.soc.27.1.363

Newman, T. (2018, February 7). Sex and gender: What is the difference? Retrieved from Medical News Today: https://www.medicalnewstoday.com/articles/232363.php

Richards, B. (2010). The Significance of The Screenplay. Inquiries Journal, 2(2). Retrieved from Inquiries Journal: http://www.inquiriesjournal.com/articles/172/the-significance-of-the-screenplay

Rogers, C. R. (1940). The Process of Therapy. Journal of Consulting and Clinical Psychology, 60(2), 163164. https://doi.org/10.1037//0022-006x.60.2.163

Rogers, C. R. (1951). Client-centered Therapy. Boston: Houghton Mifflin.

Shepard, L. A. (1979). Self-Acceptance: The Evaluative Component of the Self-Concept Construct. American Educational Research Journal, 16(2), 139-160. https://doi.org/10.2307/1162326

What is intersex? (n.d.). Retrieved November 21, 2019, from Intersex Society of North America: https://isna.org/faq/what_is_intersex/ 